\title{
A ORIGEM COMO DESTINO: TRAJETÓRIAS PROFISSIONAIS DE FAXINEIRAS TERCEIRIZADAS
}

ORIGIN AS DESTINATION: PROFESSIONAL TRAJECTORIES OF OUTSOURCED

Recebido em 05.09.2020 Aprovado em 02.12.2020

Avaliado pelo sistema double blind review DOI: https://doi.org/10.12712/rpca.v14i4.45779

\section{Filipe Augusto Silveira de Souza}

filipe.souza@fgv.br

Escola de Administração de Empresas da Fundação Getúlio Vargas-São Paulo/SP, Brasil

$\underline{000-0001-7547-8947}$

\author{
Ana Heloísa da Costa Lemos \\ aheloisa@iag.puc-rio.br \\ Programa de Pós-Graduação em Administração de Empresas do Departamento de Administração da PUC-Rio - \\ Rio de Janeiro/RJ, Brasil \\ $\underline{0000-0001.6222 .6628}$
}

\section{Resumo}

Este artigo investigou a influência exercida pelo contexto de origem nas trajetórias de carreira de prestadoras de serviço de limpeza. Adotou-se, enquanto quadro teórico, a abordagem disposicional neobourdieusiana proposta por Jessé Souza. A abordagem metodológica privilegiou o uso de histórias de vida para analisar as trajetórias profissionais estudadas. Os resultados obtidos ilustram que os contextos de origem das entrevistadas, caracterizados por reduzidos volumes de capital e acentuada desorganização social, condicionaram suas trajetórias profissionais, marcadas por inserções pouco qualificadas em um mercado de trabalho competitivo. Tais resultados contribuem para colocar em xeque abordagens voluntaristas de carreiras que enfatizam a agência individual.

Palavras-chave: Carreira. Classe social. Capital familiar. Desigualdade social.

\begin{abstract}
This paper investigates the influence of the context of origin in the social construction process of outsourced cleaning service providers' careers. As a theoretical framework, the neo-Bourdieusian dispositional approach proposed by Jessé Souza was adopted. The methodological approach privileged the life histories to analysis the professional trajectories. The results of the research illustrate that the contexts of origin portrayed by the interviewees, characterized by low volumes of capital and social disorganization, conditioned their professional trajectories, marked by poorly qualified insertions in the labor market. Such results contribute to put in check the voluntary career approaches that emphasize the individual agency.
\end{abstract}

Keywords: X Careers. Social class. Familiar capital. Inequality. 


\section{Introdução}

Longe de primar pela homogeneidade, o mundo do trabalho atual caracteriza-se por sua crescente polarização, precariedade e vulnerabilidade (Kost, Fiesele, \& Wong, 2020). Em um cenário marcado por mudanças tecnológicas, mobilidade do capital, reestruturação organizacional e liberalismo econômico na condução de políticas públicas (Tomlinson et al., 2018), escasseiam as oportunidades de ascensão organizacional, ao mesmo tempo em que aumentam a insegurança e a fluidez dos vínculos de trabalho (Foster, Hassard, Morris, \& Wolfram, 2019). À crescente diversificação da mão de obra, corresponde o crescimento de modalidades atípicas de trabalho, como o temporário, o em tempo parcial e o terceirizado (Sullivan \& Baruch, 2009).

No tocante ao instituto da terceirização, esta é considerada por alguns autores (Antunes \& Druck, 2014) como a representação por excelência do processo de institucionalização da flexibilização dos vínculos empregatícios, por sua vez relacionado à crescente precarização estrutural do trabalho. Cabe observar que em setores como o de conservação e limpeza, cujo subgrupo "prestador de serviço de limpeza terceirizada" corresponde ao foco de análise desta pesquisa, a precariedade objetiva e subjetiva do trabalho tende a se acentuar. Por um lado, os trabalhadores do setor vivenciam aspectos tipicamente relacionados ao instituto da terceirização, como a depressão dos salários e benefícios; a intensificação do processo de trabalho; o aumento da insegurança decorrente da fragilidade dos vínculos empregatícios; os níveis de responsabilidade, cobrança e controle crescentes; e o maior risco de acidentes no trabalho (Herod \& Aguiar, 2006). Por outro, esses trabalhadores experimentam um processo de invisibilidade social (Lara, Marra \& Fernandes, 2020) ou pública (Costa, 2004), condição associada a formas de trabalho subalternas e desqualificadas, que remete a uma modalidade particular de humilhação correspondente a uma "espécie de desaparecimento psicossocial de um homem no meio de outros homens" (Costa, 2008, p.1).

Nesse sentido, Bezuidehout e Fakier (2006) destacam o incentivo organizacional ao controle pelos pares, bem como a prática do exercício arbitrário do poder pelos supervisores, inclusive por meio de gritos e xingamentos. Ainda segundo os autores, a relação entre terceirização e redução dos níveis de remuneração e benefícios é um sinal de que o corte de custos organizacionais se dá "à custa daqueles trabalhadores na base da hierarquia social" (Bezuidehout \& Fakier, 2006, p. 54). A despeito das condições adversas retratadas, a inserção no mercado de limpeza corporativo é vista por trabalhadoras do setor como uma alternativa superior à condição de empregada doméstica, trabalho julgado mais pesado e com menos direitos sociais e trabalhistas (Diogo \& Maheirie, 2007). Por outro lado, a condição de terceirizado, quando comparada ao status de trabalhador efetivo, pode ensejar sentimentos de inferioridade e vergonha, em geral associado ao desejo do terceirizado de fazer parte do quadro efetivo de profissionais (Costa, 2007).

De especial relevância para o objetivo deste artigo, a pesquisa etnográfica realizada por Lara, Marra e Fernandes (2020), com prestadoras de serviço de limpeza terceirizadas, lotadas em uma universidade pública no Estado de Minas gerais, retrata um cenário específico de imobilidade social, caracterizado pela transmissão ocupacional de mãe para filha. Reportam-se, assim, resultados que iluminam a permanência da influência do contexto familiar sobre as trajetórias individuais.

Em paralelo ao crescimento das formas precárias de ocupação, o último quarto de século do segundo milênio foi o momento de emergência de uma multiplicidade de teorias nas ciências sociais, cuja tendência primordial é a valorização da agência, a exemplo da corrente denominada modernização reflexiva (Beck, 1997). Traduzida em uma maior oferta de escolhas aos indivíduos, o poder superior de agência é associado, entre outros aspectos, a um processo de diferenciação social correspondente à perda de centralidade de instituições tradicionais como família, igreja e escola. Nessa direção defende-se a possibilidade de representação das trajetórias individuais nos termos de uma construção biográfica do tipo "faça você mesmo" (Beck, 1997). 
A partir de meados da década de 1990, os reflexos de tais tendências se fazem notar, no campo de estudo de carreiras, com a emergência de novos conceitos de carreira, tais como carreiras sem fronteiras (Arthur \& Rousseau, 1996) e proteana (Hall \& Moss, 1998). Unidos pela ênfase no poder de agência, esses construtos tendem a defender a necessidade de transferência da responsabilidade pela gestão das carreiras aos indivíduos, em linha com o discurso do mérito que perpassa a lógica neoliberal (Roper, Ganesh, \& Inkson, 2012). A carreira emerge, assim, "como o resultado das escolhas feitas pelos proprietários individuais" (Van der Heijder \& De Vos, 2015, p. 8).

Adicionalmente ao excessivo voluntarismo, cujo corolário é a desatenção às condicionantes estruturais que impactam as trajetórias profissionais, as novas modalidades de carreira são igualmente criticadas pelo foco restrito de análise, usualmente voltado às carreiras gerenciais e profissionais (Guest \& Sturges, 2007). No âmbito desse debate, não parece ser levada em conta a natureza desigual da sociedade do trabalho atual, caracterizada por uma força de trabalho fragmentada, com "produtores informacionais", de um lado, e "mão de obra genérica substituível", do outro, sem falar no "segmento significativo da sociedade formado por indivíduos cujo valor como trabalhadores/consumidores já está desgastado e cuja importância como pessoa é ignorada" (Castells, 1999, p. 423).

Defende-se, neste artigo, que a emergência, no início dos anos 2000, de uma perspectiva de carreira assentada sobre a teoria da prática bourdieusiana pode ser lida como uma reação à pouca consideração das dimensões contextuais de análise dominante nos estudos de carreira (Mayrhofer, Meyer, \& Steyrer, 2007). Pesquisas realizadas sob a abordagem bourdieusiana destacam as múltiplas barreiras enfrentadas pelos indivíduos, ao longo de suas trajetórias profissionais, em virtude de aspectos tais como envelhecimento (Tempest \& Coupland, 2017), cultura/etnia (Eggenhofer-Rehart et al., 2018), gênero (Fernando, Cohen, \& Duberley, 2018) e origem social (Iellatchitch, Mayrhofer, \& Meyer, 2005).

A despeito dos esforços empreendidos até o momento para a difusão de tal perspectiva, nota-se, ainda, um reduzido número de pesquisas que privilegiam a categoria classe social, apesar de tratar-se de uma dimensão transversal no arcabouço teórico bourdieusiano. Com vistas a contribuir para o debate acerca dos limites das perspectivas voluntaristas de carreira e enfatizar a importância do marcador classe social, nessa discussão (Inkson, Gunz, Ganesh, \& Roper, 2012), objetivou-se, na presente pesquisa, compreender as influências exercidas pelo contexto de origem no processo de construção das carreiras de trabalhadoras das classes populares que atuam em serviços terceirizados de limpeza. Adicionalmente, a investigação pretendeu jogar luz sobre as carreiras de trabalhadores das classes populares, territórios pouco explorados nos estudos de carreira (Baruch \& Vardi, 2016).

Adotou-se no presente artigo a perspectiva neobourdieusiana proposta pelo sociólogo brasileiro Jessé Souza, cujo foco central é a compreensão do processo (re)produção social no contexto brasileiro (Souza, 2012a). Alternativamente às teses dominantes do processo de modernização brasileira que apontam o personalismo e o patrimonialismo como fatores causalmente associados à nossa singularidade, Souza (2012a) diferencia as sociedades periféricas, como a brasileira, em comparação com as sociedades desenvolvidas do Ocidente, com base na desigualdade social assentada, no primeiro caso, sobre a (re)produção de uma ralé estrutural como fenômeno de massa. Em sua visão, os indivíduos dessa classe social compartilham um habitus precário, caracterizado pela carência de disposições psicossociais como disciplina, pensamento prospectivo e autorresponsabilidade, pressupostos para que "seja um indivíduo, seja um grupo social possa ser considerado produtivo e útil em uma sociedade do tipo moderno e competitivo, podendo gozar de reconhecimento individual" (Souza, 2006, p. 36).

Para alcançar os objetivos propostos, estruturou-se este artigo em cinco partes, incluindo esta introdução. $\mathrm{Na}$ segunda e terceira partes apresentam-se, respectivamente, considerações relativas ao arcabouço teórico e ao percurso metodológico adotado na pesquisa. Na sequência apresenta-se a análise dos resultados do artigo e, ao fim, as conclusões. 


\section{Desenvolvimento teórico}

\section{Teoria da prática: considerações gerais}

A Teoria da Prática avançada por Bourdieu (2013) pode ser lida como uma abordagem epistemológica relacional que busca se afastar de concepções voluntaristas e deterministas da vida social (Emirbayer \& Johnson, 2008). Ao privilegiar o resgate da ação habitual como componente central da reflexividade humana, o autor se distancia da concepção moderna de ator racional sem, contudo, "anular o agente na sua verdade de operador prático de construção do objeto" (Bourdieu, 2010, p. 62).

Entre os conceitos propostos pelo autor merece destaque o tripé campo, capital e habitus, a partir do qual pretende "capturar a lógica mais profunda do mundo social" (Bourdieu, 2013, p. 12). Definida como "estrutura de diferenças" (Bourdieu, 2013, p. 50), a noção de campo remete à posição ocupada pelos indivíduos em um espaço tridimensional, composto pelo seu volume e estrutura de capital, bem como pela sua trajetória, reflexo do engajamento pessoal nas múltiplas esferas de atividade, com destaque para a familiar e a educacional (Bourdieu, 2013).

No tocante à noção de capital, destaca-se a ampliação do conceito para além da dimensão econômica, com vistas a abarcar os aspectos cultural, social e simbólico. Ao passo que o capital econômico diz respeito às distintas modalidades de riqueza material e monetária, o capital cultural corresponde a uma "forma mais dissimulada de transmissão hereditária do capital" (Bourdieu, 2015, p. 84), composta por três espécies ou estados. No estado incorporado, refere-se às formas de agir, pensar e perceber incorporadas pelos indivíduos, que lhes faculta exercitar, de forma irrefletida, práticas e comportamentos consistentes com a posição que ocupam no espaço social e nos distintos campos especializados (Bourdieu, 1990). Em estado objetivado, remete à propriedade de bens culturais como obras de arte e livros, cuja apreciação estética pressupõe a incorporação de um capital cultural específico; por fim, o capital cultural institucionalizado encontra-se usualmente associado a certificados educacionais ou profissionais diversos. O capital social, por sua vez, é definido como o conjunto de recursos derivados da participação durável em redes de relacionamentos ou conexões sociais, e guarda relação direta com a vinculação à determinada classe social, à família e à múltiplos grupos sociais.

No âmbito do quadro referencial do autor, o habitus emerge como plano intermediário que conecta estrutura social e práticas dos agentes. Fruto da internalização inconsciente da coletividade pelos indivíduos, via um longo processo prático de aprendizagem, o habitus é definido como "conjunto de relações históricas 'depositadas' no interior dos corpos sob a forma de esquemas de percepção, apreciação e ação” (Bourdieu \& Wacquant, 1992, p. 16).

A noção de habitus estrutura-se a partir da assimilação de formas de classificação, ou sistemas simbólicos, que remetem às disputas entre as classes pelo "monopólio da violência simbólica legítima", ou seja, o "poder de impor - e mesmo de inculcar - instrumentos de conhecimento e expressão (taxinomias) arbitrários - embora ignorado como tais - da realidade social” (Bourdieu, 2010, p. 12).

Cabe observar, que a prevalência do recorte de classe no arcabouço bourdieusiano não impede o sociólogo francês de reconhecer a dominação de gênero como a "forma paradigmática de violência simbólica” (Bourdieu e Wacquant, 2002, p. 170). Em “A dominação masculina” (Bourdieu, 1995), propõe-se que a naturalização da divisão sexual prevalente no mundo social relaciona-se ao fato de $\mathrm{O}$ patriarcalismo ser "uma instituição que está inscrita há milênios na objetividade das estruturas sociais e na subjetividade das estruturas mentais" (Bourdieu, 1995, p. 133). Dificulta-se, assim, o confronto com realidades alternativas e o consequente questionamento do processo de dominação simbólica.

É a partir da análise antropológica das relações de dominação entre os sexos na sociedade Cabila, na Argélia, que Bourdieu explicita a construção social de "naturezas" de gênero praticamente opostas, em que às mulheres caberiam os trabalhos domésticos, bem como os trabalhos externos julgados os "mais 
sujos (como o transporte do estrume), os mais monótonos, os mais penosos e os mais humildes" (Bourdieu, 1995, p. 138). Em última instância, a obra do autor pode ser lida como um esforço de desnaturalização de diferenças socialmente construídas, subjacentes a múltiplas formas de desigualdade.

\section{Modernidade, habitus precário e (re)produção da desigualdade social}

Em oposição às teses dominantes do processo de modernização brasileira que propõem o personalismo e o patrimonialismo como fatores explicativos da nossa singularidade, Souza (2012a) aponta como traço distintivo entre as sociedades ocidentais desenvolvidas e periféricas, a (re)produção, no segundo caso, de uma "ralé" estrutural. Em sua visão, objetiva-se, com o uso de tal nomenclatura, frisar a (re)produção de uma classe de despossuídos, que desprovidos das disposições psicossociais requisitadas pelo mercado de trabalho competitivo, situam-se em suas franjas ou exibem o status de desempregados.

A teoria neobourdieusiana proposta por Souza (2012a) caracteriza-se pela articulação das dimensões socioeconômica, cultural e moral de análise; a partir da conjugação dos arcabouços de Bourdieu (1990) e do filósofo canadense Charles Taylor (2013), Souza (2012a) busca superar as unilateralidades das propostas de ambos os autores, integrando, em um todo coerente, poder e moralidade. Da filosofia moral de Taylor (2013), Souza (2012a) apropria-se, sobretudo, da tese segundo a qual a emergência da moderna noção de identidade dominante no Ocidente, pautada pelo enaltecimento do individualismo, da razão, do desempenho e da liberdade, relaciona-se ao compartilhamento, por amplos setores de uma sociedade, de esquemas de ação, percepção e apreciação, condicionados por configurações morais precedentes.

A partir de um trajeto que vai de Platão à Reforma Protestante, passando por Santo Agostinho, Descartes e Locke, Taylor (2013) propõe o conceito de self pontual para se referir a "uma concepção contingente e historicamente específica de ser humano, presidido pela noção de calculabilidade, raciocínio prospectivo, autocontrole e trabalho produtivo" (Souza, 2006, p. 30). Tal configuração identitária é sugerida por Taylor (2013) como pressuposto da autoestima e da dignidade, conceito este que remete ao conceito de cidadania e, portanto, à titularidade de direitos subjetivos universais, cujo exercício pressupõe a noção de igualdade (Souza, 2006).

Se para Taylor (2013), a genealogia da hierarquia social no Ocidente remete a uma topografia moral em que a noção do self pontual é assumida como valor superior, para Bourdieu (1990) a sociedade seria mais bem compreendida nos termos de uma topografia social, em que a posição social ocupada pelos indivíduos corresponde ao seu portfólio de capitais. Para Souza (2012a), ambos os autores valorizam, no contexto da modernidade tardia, a dimensão da autenticidade, em detrimento da dignidade, o que pode ser explicado pela influência exercida, em seus arcabouços teóricos, pelas conquistas no âmbito do Welfare State nas décadas de 1970 e 1980. Na visão de Souza (2012a), tanto a assunção do self pontual como representação de uma ontologia universal, quanto a generalização do conceito de habitus a partir da valorização da dimensão estética, correspondem a leituras etnocêntricas da realidade social.

Um dos elementos constitutivos do arcabouço teórico proposto por Souza (2012a) é a proposta de uma tipologia tripartite do habitus, em que se assume a inexistência, em contextos periféricos, de um consenso normativo prévio ao processo de modernização, calcado na valorização de um ideal identitário correspondente ao self pontual. Diversamente das nações desenvolvidas do Ocidente, países como o Brasil não se caracterizam pelo compartilhamento, generalizado do status de cidadania e, portanto, de condições dignas de existência (Souza, 2009). Em linhas gerais, Souza (2012a) associa as modalidades de habitus precário, primário e secundário a distintas modalidades de existência: indigna, digna e autêntica, respectivamente.

A tese desenvolvida pelo sociólogo paulista Florestan Fernandes em A integração do negro na sociedade de classes (1978), segundo a qual a pobreza extrema, aliada a padrões familiares disruptivos, constituem um cenário avesso ao desenvolvimento das disposições psicossociais demandadas para a inserção em uma sociedade moderna competitiva, é de fundamental para a conceituação do habitus precário (Souza, 
2012a). Para este autor, a deformação impingida ao negro pelo regime escravocrata não lhe facultou o padrão de socialização pressuposto pela atividade capitalista, ou seja, tolheu-lhe da "capacidade sociodinâmica de agir segundo os modelos de organização do comportamento, da personalidade, ou das instituições impostos pela ordem social competitiva" (Fernandes, 1978, p.68).

Por um lado, Souza (2012a, p.156) apropria-se da tese de Fernandes (1978) que associa a "ausência da unidade familiar como instância moral e social básica", herança de uma ordem escravocrata contrária à organização familiar e comunitária dos escravos, à constituição de uma organização da personalidade estranha à ordem competitiva emergente. Por outro, propõe a ampliação da proposta de Fernandes (1978) "para abranger também os estratos despossuídos e dos dependentes em geral e de qualquer cor" (Souza, 2012a, p.158), salientando, inclusive, que a noção de 'ralé nacional' ou 'gentinha' proposta por Fernandes (1978), já abarcava tanto negros quanto dependentes rurais brancos.

A releitura de Fernandes (1978), a partir da perspectiva bourdieusiana, facultou à Souza (2012a, p.167) cunhar o termo habitus precário para se referir a uma estrutura de personalidade desprovida daquelas disposições "nada óbvias do mundo do trabalho moderno: disciplina, autocontrole, e comportamento e pensamento prospectivo" (Souza, 2012b, p. 51), condicionada pela combinação de um ambiente familiar desestruturado e baixos níveis de capital cultural e econômico.

O habitus primário é proposto por Souza (2012a, p.167) para se referir à incorporação de esquemas de avaliação, percepção e ação, incorporados por um processo de aprendizagem histórico, que permite aos indivíduos de uma dada sociedade compartilhar um senso de dignidade, seja no tocante "à eficácia social da regra jurídica da igualdade", seja "no sentido não jurídico de levar o outro em consideração" (Souza, 2006, p. 37). Corresponde, assim, a um patrimônio disposicional que possibilita ao indivíduo "ser considerado produtivo e útil em uma sociedade de tipo moderno e competitivo, podendo gozar de reconhecimento social".

Diversamente das nações periféricas, que se distinguem pela (re)produção do habitus precário entre contingentes populacionais expressivos, as sociedades desenvolvidas do Ocidente caracterizam-se pelo amplo compartilhamento do habitus primário entre os seus membros (Souza, 2012a). Por sua vez, o habitus secundário, elemento primordial de distinção na obra de Bourdieu (2013), remete à apropriação sociossimbólica seletiva de recursos escasso, que pressupõe uma competência estética diferencialmente distribuída em favor das classes privilegiadas (Souza, 2012a).

Por fim, cabe observar que o arcabouço teórico proposto por Souza (2012a) constitui-se no ponto de partida a partir do qual o autor avança um programa empírico de pesquisa, cujo foco central é o compreender o fenômeno da gênese e da reprodução da desigualdade social brasileira. É nesse contexto que se inserem as obras A ralé brasileira (2009) e Os batalhadores brasileiros (2012b).

\section{Procedimentos metodológicos}

A adoção de uma abordagem narrativa nesta pesquisa deu-se pela compreensão de que as experiências subjetivas se constituem não apenas em via de acesso privilegiado aos sistemas de percepções e significações individuais (Denzin \& Lincoln, 2010), mas também às estruturas e aos processos objetivos que condicionam "formas particulares de vida material, produção e reprodução, trabalho e consumo" (Bertaux, 1999, p.6). Mais do que reflexo fiel das experiências vividas pelo narrador, histórias de vida refletem um recorte particular de uma trajetória individual e são particularmente fecundas para suportar a análise de processos de mobilidade e exclusão social, de sociabilidades e de trajetórias profissionais (Barros \& Lopes, 2014).

A adoção conjunta, nesta pesquisa, do arcabouço bourdieusiano e das histórias de vida, como meio de acesso às experiências vividas e representadas das entrevistadas - faxineiras terceirizadas - pode ensejar eventuais críticas dirigidas à potencial incongruência entre ambos. Assim, não há como escapar à 
tematização da aparente contradição entre as críticas dirigidas por Bourdieu a metodologias narrativas em geral (Bourdieu, Chamboredon, \& Passeron, 2005), e à história de vida em particular (Bourdieu, 2005), e o seu uso pelo autor em suas pesquisas com camponeses e subproletários argelinos (Bourdieu, 2004) e, na França, em A miséria do mundo (Bourdieu, 1999).

Em linha com a análise de Barrett (2015), propõe-se, neste artigo, que a crítica empreendida por Bourdieu às histórias de vida, sobretudo em A ilusão biográfica (Bourdieu, 2005), dirige-se a uma compreensão particular da história de vida. Tal perspectiva pressupõe a trajetória individual (vida) como "um percurso orientado, um deslocamento linear, unidirecional" (Bourdieu, 2005, pp.183-184), a qual corresponde à interpretação do indivíduo enquanto ator racional provido de um "senso de agência e dirigido por um coerente e abrangente "propósito" (Barret, 2015, p.2). O que se critica é o fato de que, ao interpretar a prática como um processo de escolha individual, tal perspectiva falha em reconhecer a existência de estruturas sociossimbólicas que condicionam e são condicionadas pelas ações e percepções individuais. A adoção a-histórica das histórias de vida como meio de acesso às trajetórias individuais não se reveste, na visão do autor, da devida vigilância epistemológica, definida como a "subordinação da utilização das técnicas e conceitos a uma interrogação sobre as condições de sua validade" (Bourdieu, Chamboredon, \& Passeron, 2005, p.14).

Em linha com a proposta de Bourdieu (1999), buscou-se, neste artigo, conciliar metas à primeira vista contraditórias: objetivar as condições de existência individuais e os pontos de vista correspondentes, ao mesmo tempo em que se reconhece a singularidade das trajetórias em geral e das carreiras em particular.

A seleção da categoria de faxineiras terceirizadas como sujeitos de pesquisa deu-se em virtude dos seguintes aspectos: (i) a relevância da atividade no tocante à geração de postos de trabalho nas últimas décadas, sobretudo a partir dos anos 2000 (Pochmann, 2014), e (ii) a potencial contribuição desta pesquisa aos estudos recentemente empreendidos nos estudos organizacionais associados a distintas modalidades de prestação de serviços de limpeza, praticados seja na condição de empregada doméstica (Silva, Bortolini, \& Oltramari, 2018), seja na de faxineira terceirizada (Lara, Marra, \& Fernandes, 2020) ou na de gari (Meira, Gomes, \& Amaral, 2019).

No que diz respeito ao número de informantes, foram selecionadas oito trabalhadoras, conforme descrição contida no Quadro 1. O perfil das entrevistadas corrobora o fato de a ocupação refletir um recorte específico não só de classe, mas, igualmente, de gênero e etnia. Segundo pesquisa elaborada pelo DIEESE (2011), a atividade de conservação e limpeza pode ser segregada em três grandes grupos: asseio e conservação (limpeza em estabelecimentos comerciais, industriais e de serviços), limpeza urbana e manutenção de áreas verdes, destacando-se que, ao passo que no primeiro caso o contingente feminino alcança aproximadamente $60 \%$, nos demais é pouco representativa - em torno de 1\% e 9\%, respectivamente. Igualmente relevante é o contraste em termos de etnia, haja vista que em torno de $73 \%$ dos entrevistados declararam-se negros ou pardos. Cabe destacar que a seleção dos entrevistados não pré-definiu recorte de gênero e etnia, mas apenas ocupacional (asseio e conservação), o que não impediu que a totalidade das participantes fosse do gênero feminino, e, em sua maioria, negras e pardas. 
Quadro 1 - Descrição das entrevistadas

\begin{tabular}{|c|c|c|c|c|c|c|}
\hline Entrevistadas & Idade & Formação educacional & $\begin{array}{c}\text { Inserção profissional } \\
\text { (idade) }\end{array}$ & Profissões exercidas & $\begin{array}{l}\text { Primeira } \\
\text { Gravidez }\end{array}$ & $\begin{array}{l}\text { Núm ero } \\
\text { de filhos }\end{array}$ \\
\hline Alessandra & 29 anos & Ensino médio incompleto & 16 anos & $\begin{array}{c}\text { Auxiliar de serviços gerais e } \\
\text { doméstica }\end{array}$ & 19 anos & 2 \\
\hline Monique & 33 anos & Fundamental com pleto & 13 anos & $\begin{array}{c}\text { Auxiliar de serviços gerais e } \\
\text { doméstica }\end{array}$ & 17 anos & 2 \\
\hline Nazaré & 56 anos & Fundamental com pleto & 14 anos & $\begin{array}{l}\text { Auxiliar de serviços gerais, } \\
\text { doméstic a, babá e artesã }\end{array}$ & 29 anos & 2 \\
\hline Bruna & 29 anos & Fundamental inc ompleto & 14 anos & Auxiliar de serviços gerais e doceira & 13 anos & 2 \\
\hline Georgette & 59 anos & Fundamental com pleto & 18 anos & $\begin{array}{l}\text { Auxiliar de serviços gerais, } \\
\text { doméstic a e balc onista }\end{array}$ & 16 anos & 2 \\
\hline Regina & 52 anos & Ensino médio completo & 40 anos & $\begin{array}{c}\text { Auxiliar de serviços gerais e } \\
\text { doméstica }\end{array}$ & 21 anos & 3 \\
\hline Andrea & 40 anos & Fundamental inc ompleto & 12 anos & $\begin{array}{c}\text { Auxiliar de serviços gerais, } \\
\text { doméstica e babá }\end{array}$ & 17 anos & 3 \\
\hline Adriana & 37 anos & Fundamental inc ompleto & 19 anos & Auxiliar de serviços gerais & 17 anos & 3 \\
\hline
\end{tabular}

Fonte: Elaborado pelos autores.

Em virtude da abordagem disposicional adotada, segundo a qual os modos de pensar, agir e perceber estão associados à posição ocupada no espaço social, a preocupação maior, com o campo, não se relacionou ao número de entrevistadas, mas à profundidade perseguida nos processos de apreensão e análise das histórias de vida, razão pela qual foram realizadas de duas a três entrevistas, em média com uma hora de duração, com cada sujeito.

Uma vez apresentadas as considerações julgadas relevantes sobre o percurso metodológico, o tópico seguinte é dedicado à análise dos resultados da pesquisa.

\section{Apresentação e análise dos resultados}

A análise das narrativas das entrevistadas foi realizada com os objetivos de: (i) compreender as influências exercidas pelo contexto de origem no processo de construção das carreiras de trabalhadoras das classes populares que atuam em serviços terceirizados de limpeza; (ii) privilegiar as dimensões constitutivas das carreiras - espaço, identidade e tempo (Gunz \& Mayrhofer, 2015). A partir desses objetivos foram privilegiados os seguintes temas que, na sequência, estruturam a análise: a "reprodução sócioocupacional" (espaço/campo), a "normalização da precariedade", e "gravidez precoce, tempo e habitus precário".

Com vistas à estruturação do processo de análise, optou-se nesta pesquisa pela adoção do método de análise temática. Em linha com a proposta de King (2004), procedeu-se à elaboração de um template, cujo desenvolvimento conjugou categorias definidas a priori e emergentes, e que foi constituído por códigos de primeira, segunda, terceira e quarta ordens, conforme Quadro 2, a seguir. Ao passo que a "trajetória familiar" foi adotada como código de primeira ordem; a "condição social de origem", o "capital familiar" e o(s) "ponto(s) de virada" (turning points) foram propostos como códigos de segunda ordem. No primeiro caso, adotaram-se dois códigos de terceira ordem - "imobilidade social (nível educacional e profissional próprio e dos pais)" e "experiências subjetivas de privação" -, e no segundo caso, o "habitus precário", caracterizado pela coexistência de um cenário de desestruturação familiar e um reduzido volume de capitais. Já no último caso, emergiu o código de terceira ordem "gravidez e conjugalidade". 
Quadro 2: Códigos adotados na pesquisa

\begin{tabular}{lll}
\hline $\mathbf{1}^{\mathbf{a}}$ ordem & $\mathbf{2}^{\mathbf{a}}$ ordem & $\mathbf{3}^{\mathbf{a}}$ ordem \\
\hline Trajetória familiar & Condição social de origem & $\begin{array}{l}\text { Imobilidade social (nível educacional e } \\
\text { profissional próprio e dos pais) }\end{array}$ \\
\cline { 2 - 3 } & Capital Familiar & $\begin{array}{l}\text { Habitus precário (desestruturação } \\
\text { familiar e reduzido volume de capitais) }\end{array}$ \\
\cline { 2 - 3 } & Pontos de virada (turning points) & Gravidez e conjugalidade precoces \\
\hline
\end{tabular}

Fonte: Elaborado pelos autores.

É importante salientar que a análise empreendida nesta pesquisa abarcou as condições sociais de origem em suas dimensões objetiva e subjetiva, privilegiando-se, assim, o acesso ao fundo existencial comum subjacente às histórias de vida das entrevistadas, e os aspectos singulares capturados a partir de suas narrativas.

\section{Reprodução sócio-ocupacional}

Primeiramente, argumenta-se que as carreiras individuais das entrevistadas foram, em grande medida, condicionadas pelo status ocupacional e educacional dos pais, proxy para o capital cultural -herança imaterial passível de transferência interpessoal ao longo do processo de socialização (Bourdieu, 2015). Pressupõe-se, em linha com resultados de pesquisas prévias, a existência de uma correspondência entre a distribuição assimétrica dos recursos familiares (econômicos, sociais e culturais) e as desigualdades sociais vivenciadas pelos indivíduos nos mais diversos campos ao longo de suas trajetórias (MacDonald \& Marsh, 2005; Côté, 2011).

As informações dispostas na Quadro 3 ilustram a correspondência entre as condições de origem dos pais e de destino das entrevistadas, representadas pelas respectivas situações educacionais e ocupacionais. Essa correspondência é congruente com achados de pesquisas que revelam ser a reprodução social, ainda hoje, o resultado mais provável, evidenciando o forte condicionamento das chances de vida pela estrutura de oportunidades (Atkinson, 2012).

Quadro 3 - Condições sociais de origem

\begin{tabular}{|c|c|c|c|c|c|c|}
\hline \multirow[b]{2}{*}{ Entrevistadas } & \multicolumn{2}{|c|}{ Nivel educacional } & \multicolumn{2}{|c|}{ Ocupação } & \multicolumn{2}{|c|}{ M oradia } \\
\hline & Pai & Mãe & Pai & Mãe & Dormitórios & Moradores (\#) \\
\hline Alessandra & $\begin{array}{l}\text { Fundamental } \\
\text { incompleto }\end{array}$ & $\begin{array}{l}\text { Fundamental } \\
\text { incompleto }\end{array}$ & $\begin{array}{l}\text { Falecido (trabalhou na } \\
\text { contravenção) }\end{array}$ & $\begin{array}{c}\text { Auxiliar de serviços gerais, } \\
\text { gari e carteira na } \\
\text { comunidade e entregadora } \\
\text { de jomal }\end{array}$ & Dois quartos e sala & 16 \\
\hline Monique & $\begin{array}{l}\text { Fundamental } \\
\text { incompleto }\end{array}$ & $\begin{array}{l}\text { Fundamental } \\
\text { completo }\end{array}$ & $\begin{array}{c}\text { Desempregado } \\
\text { (trabalhou como } \\
\text { gesseiro) }\end{array}$ & $\begin{array}{c}\text { Auxiliar de senviços gerais } \\
\text { e cozinheira }\end{array}$ & Quarto e sala & 7 \\
\hline Maria de Nazaré & $\begin{array}{l}\text { Fundamental } \\
\text { incompleto }\end{array}$ & Analfabeta & $\begin{array}{l}\text { Falecido (trabalhou } \\
\text { como agricultor) }\end{array}$ & Agricultora e dona de casa & $\begin{array}{c}\text { Quarto e sala } \\
\text { (taipa), depois dois } \\
\text { quartos e sala } \\
\text { (alvenaria) }\end{array}$ & 6 \\
\hline Bruna & $\begin{array}{c}\text { Fundamental } \\
\text { completo }\end{array}$ & $\begin{array}{c}\text { Fundamental } \\
\text { completo }\end{array}$ & $\begin{array}{l}\text { Auxiliar de transporte } \\
\text { / Gari na comunidade }\end{array}$ & Auxiliar de serviços gerais & Conjugado & 9 \\
\hline Georgette & Analfabeto & Analfabeta & Mestre de obra & Dona de casa & Dois quartos e sala & 4 \\
\hline Regina & $\begin{array}{l}\text { Fundamental } \\
\text { incompleto }\end{array}$ & $\begin{array}{l}\text { Fundamental } \\
\text { incompleto }\end{array}$ & $\begin{array}{l}\text { Mecânico de } \\
\text { automóvel }\end{array}$ & Dona de casa & Conjugado & 12 \\
\hline Andrea & N.D & N.D & N.D. & Doméstica & Conjugado & 8 \\
\hline Adriana & $\begin{array}{l}\text { Fundamental } \\
\text { incompleto }\end{array}$ & $\begin{array}{l}\text { Fundamental } \\
\text { incompleto }\end{array}$ & $\begin{array}{l}\text { Mecânico de } \\
\text { automóvel }\end{array}$ & Dona de casa & Conjugado & 12 \\
\hline
\end{tabular}

Fonte: Elaborado pelos autores. 
No tocante à reprodução da atividade ocupacional, salta aos olhos o fato de as mães das entrevistadas terem ocupações que refletem distintas combinações das seguintes atividades: auxiliar de serviços gerais, doméstica e dona de casa. Corroboram-se, assim, os achados da pesquisa de Lara, Marra e Fernandes (2020), que investigou o processo de formação das identidades profissionais de faxineiras terceirizadas alocadas em uma universidade pública e que revelou o fato de, em meio a uma existência marcada por preconceitos e invisibilidade social, as entrevistadas reproduzirem a trajetória profissional de suas mães.

Alega-se, ainda, que a inserção desde cedo de mães e de filhas na rotina do trabalho doméstico configurase em um mecanismo de aprendizagem desses sujeitos, imbricado a uma ideologia patriarcal caracterizada por um duplo padrão de moralidade, que limita as possibilidades de ação da mulher à esfera doméstica, especialmente ao serviço doméstico, e confere ao gênero masculino o monopólio das oportunidades de ação no domínio público (Rosa, 2016). Já no caso dos pais das entrevistadas, apesar de uma maior variabilidade das ocupações, destaca-se a natureza manual dessas atividades e sua desvinculação de credenciamento profissional formal. No tocante à formação educacional, verificou-se que os pais e as mães das entrevistadas possuem, em sua maioria, o ensino fundamental incompleto.

Todavia, essa não é toda a história vivida pelas mulheres que participaram desta pesquisa; entre o início de suas trajetórias e o momento presente, descortinaram-se vidas ao mesmo tempo singulares e coletivas. Se por um lado, expressam combinações singulares das múltiplas linhas de experiência percorridas individualmente, por outro se encontram inseridas em um horizonte de possíveis que remete ao seu volume e estrutura de capital. Um mergulho em suas narrativas revelou que, em grande parte, tais caminhos foram descontínuos, não planejados, incertos e povoados de experiências vividas, e/ou representadas, que trazem consigo a marca da privação, do desrespeito e da humilhação, mas também sinais de resiliência, disposição para o trabalho, esperança e solidariedade.

\section{A normalização da precariedade}

A correspondência entre as dimensões simbólica e material (Bourdieu, 2013) fez-se evidente na representação particular que as entrevistadas fazem do quadro de precariedade que alcança múltiplas dimensões de suas vidas. Questionadas acerca de eventuais dificuldades enfrentadas em suas vidas, muitas das entrevistadas responderam negativamente, afirmando não terem passado por situação de privação irrestrita, traduzida como fome ou ausência de moradia.

A representação que fazem da noção de "dificuldade" pode ser lida como uma manifestação do seu habitus, reflexo, portanto, de um conjunto de relações sociossimbólicas sedimentadas sob a forma de disposições de percepção, apreciação e ação (Bourdieu \& Wacquant, 1992). Portanto, os territórios que ocupam na topografia social impactam decisivamente na formação de suas subjetividades, levando-as a relativizarem - ou mesmo minimizarem - as dificuldades vividas. É a partir desse quadro interpretativo que a narrativa a seguir deve ser compreendida:

Não sei se cheguei a passar dificuldade, porque meu pai dizia que eu era muito gordinha [...]. Quando não tinha um pão [...] minha mãe sempre dava um jeito para não ficar sem o café da manhã. (Monique).

Todavia, a crueza dos seus relatos, traduzida não só na aridez dos fatos descritos, mas também nos sentimentos expressos ao longo de suas narrativas, revela a vida dura que tiveram, ainda que não a traduzam necessariamente como uma vida de dificuldades. Nesse sentido, a trajetória familiar de Monique, descrita em seguida, contrasta com a descrição anterior que utiliza para sumarizar as dificuldades enfrentadas em sua infância.

Quadro 4 - A trajetória familiar de Monique: habitus precário em (re)produção 


\section{A origem como destino: trajetórias profissionais de faxineiras terceirizadas}

Monique é uma jovem mulher de pele, olhos e longos cabelos negros. Com 33 anos, casada e mãe de dois filhos, reside em uma casa humilde e de fundos no bairro Ricardo de Albuquerque, na periferia da cidade do Rio de Janeiro.

Nasceu e viveu seus primeiros anos com a mãe biológica e uma irmã, mas logo veio a morar com o pai e a madrasta. A mudança foi fruto de um apelo que ela e a irmã mais velha fizeram ao pai. Relata que deixou a casa da mãe aos 3 anos de idade em virtude dos maus tratos sofridos. Em seus próprios termos, declara: "conforme eu fazia xixi na cama, ela tirou a gente do quarto dela e botou a gente para dormir na cozinha, [onde] tinha um vão na porta de madeira, mais ou menos, sei lá, do tamanho de uma tábua. Por causa que tem quintal, passava rato pra cozinha [e] a gente dormia no meio daquele ambiente".

Após a mudança de domićlio, Monique descreve um cenário de muita dificuldade nos anos vividos com o pai, a madrasta e as cinco irmãs, com quem dividiu inicialmente um apartamento de quarto e sala. Ainda que tenham se mudado diversas vezes até parar por um bom tempo em uma kitnet, duas coisas mantiveram-se constantes: a condição de inquilinos e o fato de ela e as irmãs não terem uma cama para se deitar. Mas o nível de conforto já era superior ao de outrora, pois não dormiam mais em cima de uma coberta. "Lá tinha colchonete pra gente, aquelas coisas tudo direitinho. Coberta direitinho, travesseiro, tudo direitinho".

Demonstrou nutrir um profundo sentimento de gratidão pela madrasta, que considera como sua verdadeira mãe, pelo cuidado e pela atenção que lhe dedicou. Tal sentimento traduziu-se, entre outras coisas, em uma inserção precoce no mercado de trabalho, na condição de doméstica, aos 13 anos. Monique não se permitia ver o esforço empreendido pelos pais sem contribuir de alguma forma, tendo prometido para si mesma, desde nova, que ajudaria tão logo fosse possível. Contudo, não tardou para que deixasse esse primeiro emprego, vítima de assédio sexual. "Saí mais também por causa que o genro da mulher tava começando a se engraçar pro meu lado, porque assim... eu tinha 13 anos, mas tinha corpinho de mulherão".

O retorno ao mercado de trabalho, novamente na condição de doméstica e sem carteira assinada, traduziu-se não só na mudança física para o local em que prestava serviço, retornando para a casa dos pais apenas nos fins de semana, mas também no abandono da escola. Faz questão de destacar, ainda, que no âmbito doméstico se lembra de ter ajudado sua mãe com os afazeres diários desde os sete anos.

Ao fazer referência ao pai, relembra que, já na sua adolescência, ele demonstrava ter problemas com a bebida. Segundo ela: "meu pai chegou a cair em vala e tudo, bêbado. A gente dava banho nele no quintal, porque tava sujo de lama".

Cabe observar, por fim, que a infância e a adolescência difíceis vividas por Monique tiveram um desenlace não planejado. Com 17 anos, já namorando há algum tempo, Monique engravida. Segundo ela, "[a gravidez] veio numa troca de remédio. Quando eu era novinha, eu sempre me preveni, tomava injeção; da injeção eu troquei pro anticoncepcional, pro comprimido. Então, foi nessa troca que a [minha filha] veio". Demonstra arrependimento, creditando à maternidade precoce a perda de sua juventude.

Durante quase dez anos, dedicou-se integralmente às atividades domésticas, em virtude da desaprovação do primeiro marido da possibilidade de ela trabalhar. Contudo, o alto custo de vida, conjugado com o reduzido ordenado de seu marido, resultou em um modo de vida acentuadamente precário. Segundo Monique, "nesses dez anos eu não tinha um guarda-roupa; minha roupa vivia dentro de um saco de lixo, entendeu?".

A dificuldade crescente de custeio das despesas mínimas da casa ensejou o seu retorno ao trabalho, cabendo observar que foi na empresa em que começou a trabalhar que Monique conheceu o seu segundo marido. Diz se sentir feliz por ter encontrado uma pessoa que tem garra, disposição para trabalhar e não deixa tudo para depois. Agora, ela e o marido formam um time que planeja, por um lado, sair do aluguel e, por outro, criar os filhos para que tenham um bom trabalho no futuro, "mas, assim, não na limpeza!", frisa ela.

Fonte: Elaborado pelos autores.

A narrativa exposta para representar a trajetória familiar de Monique apresenta vários aspectos em comum com as das demais entrevistadas. Em primeiro lugar, reflete a presença de um núcleo familiar desestruturado, em linha com resultados de pesquisas que apontam que, usualmente, as famílias de baixa 
renda apresentam níveis superiores de disrupção familiar (MacDonald \& Marsh, 2005; Hardie, 2016) e contam com menor volume de recursos relacionais para lidar de forma satisfatória com essas situações (Blustein et al., 2002).

Para Souza (2012b), um cenário familiar desestruturado atinge negativamente não só a autorrelação que os membros mais jovens dessas famílias estabelecem consigo, mas a capacidade de disciplina, autocontrole e pensamento prospectivo (Souza, 2012b). Corresponde, assim, a baixos níveis de capital familiar, correlacionados pelo autor a dificuldades de desenvolvimento das disposições julgadas úteis e necessidades para a inserção em uma sociedade competitiva.

A desestruturação familiar vivenciada pelas entrevistadas revelou-se, assim, um potencial condicionante a impactar negativamente suas trajetórias, o que revela a relevância das perspectivas espacial e temporal de análise no processo de construção de carreiras (Gunz \& Mayrhofer, 2019). Por um lado, os contextos familiar e profissional encontram-se devidamente situados no espaço social mais amplo, por outro, a interrelação entre ambos relaciona-se intimamente às suas distintas temporalidades ou cronologias, inseridas no âmbito das histórias de vida das entrevistadas. Este diagnóstico está em linha com o achado de Taber e Blankemeyer (2015), segundo a qual um padrão vocacional difuso, caracterizado pela ausência de exploração, comprometimento e senso de identidade encontra-se diretamente relacionado com uma visão negativa do passado e, ainda, com uma reduzida orientação para o futuro. Portanto, ao se levar em consideração a complexa relação tempo-carreira, não se pode descartar, nas trajetórias das entrevistadas, as potenciais influências exercidas pela qualidade das relações vividas no núcleo familiar de origem sobre suas aspirações, escolhas e desenvolvimento de carreira.

$\mathrm{Na}$ amostra desta pesquisa, apenas em dois dos oito casos o núcleo familiar se revelou constituído pelo pai e pela mãe biológicos, sendo que em um deles a violência doméstica se mostrou presente desde cedo, associada a um quadro de uso abusivo de álcool. Vítima desse núcleo familiar, Regina destacou não só as consequências danosas do alcoolismo de seu pai, mas também os impactos da desestruturação familiar sobre a sua trajetória como filha mais velha.

O meu pai era uma pessoa que só vivia... era um alcóolatra, né? Que quebrava tudo dentro de casa [...]. Eu vou logo falar a verdade: eu não tive infância, minha mãe teve muito filho; eu tive que cuidar das minhas irmãs, dos meus irmãos caçulas, cuidar da casa. Eu aprendi muito, né? [...] Com 15 anos, eu conheci o meu primeiro marido, né? [...] Entrei numa outra pensando que eu ia me livrar do sofrimento que eu passei com o meu pai. Ele batia na gente, dava telefone. É! Nesse ouvido, eu vou ter que botar um aparelho auditivo devido a muita pancada que ele dava na gente. (Regina).

Igualmente digna de nota é a situação de Georgette, que morou até os 11 anos de idade em uma casa sem água encanada, localizada em uma comunidade da cidade do Rio de Janeiro. Relatou que, desde muito cedo teve que buscar água em uma localidade próxima, transportada em latas de tinta, em um trajeto percorrido a pé. Justificou essa rotina em virtude da saúde precária de sua mãe e pelo fato de seu pai morar com outra família e visitá-los esporadicamente, apenas para deixar comida. Ademais, à semelhança das outras entrevistadas, viu-se envolvida desde pequena com as atividades domésticas, especialmente em decorrência da saúde precária de sua mãe.

Ela tinha problema de bronquite, então eu pequena com $6 \ldots . .5,6$ anos, já comecei a trabalhar; já trabalhava dentro de casa. Então, quem tem bronquite não pode com poeira, né? Então, muita coisa eu fazia, entendeu? [...] Então, eu entendo [...] que já trabalhava desde esse momento. (Georgette).

O envolvimento precoce com atividades domésticas e o suporte à educação dos irmãos foram interpretados, nesta pesquisa, como sinais de antecipação da vida adulta, reportado por alguns autores como uma influência negativa nos processos de transição, sobretudo da escola para o trabalho (Kendig, Mattingly, \& Bianchi, 2014). Há quem relacione a origem social desprivilegiada com transições precoces, como parentalidade, conjugalidade e escola-trabalho - (Schoon, Peter, \& Ross, 2007), associadas, por sua 
vez, a processos de exclusão social (MacDonald \& Marsh, 2005). Nos relatos obtidos, tais vivências se fizeram presentes, merecendo destaque a maternidade precoce vivida pela maioria das entrevistadas.

\section{Habitus precário, consciência temporal e gravidez precoce}

A gravidez precoce retratada por Monique revelou-se comum a todas as narrativas, com exceção a de Nazaré, correspondendo a um evento não planejado em seis dos oito casos. Em cinco ocasiões a gravidez ocorreu em idade igual ou inferior aos 17 anos, sendo que, no caso de Bruna, a gravidez deu-se quando ela tinha apenas 12 anos. Conforme orientação normativa dominante, que atribui às mulheres a responsabilidade pelo cuidado dos filhos, todas as entrevistadas assumiram essa tarefa. Questionadas acerca do envolvimento dos companheiros na rotina doméstica, declaram:

Nada menino! Ele não fazia nada, muito mal lavava uma louça. [...] Só levava minha filha na escola e pegava, porque ele trabalhava só final de semana, que ele é DJ. (Bruna).

É ruim hein! ((risos)). Claro que não. Assim, trabalho de casa, tarefa, não. Isso aí era no começo, depois acabou ((risos)). (Andrea).

A rotina de Nazaré, nesse aspecto, é um retrato paradigmático do cotidiano destas mulheres, marcado por uma jornada tripla, resultado de uma divisão sexual do trabalho muito desigual entre homens e mulheres, suportada ideologicamente, e naturalizada por elas (Mattos, 2006):

Acho que a mulher sofre muito. Porque tem que trabalhar em casa, tem que trabalhar fora, é uma luta muito grande pra mim. Eu já acho que a mulher trabalha o dobro do homem [...]

Depois que tive minhas filhas pequena, aí eu tinha que levar pra creche [da igreja], da creche ia trabalhar [de sete às quatro da tarde]. E o pai delas pegava elas. [...] Acordava cedo, cinco horas, já ia arrumando elas pra mim levar pra creche, e da creche eu ia trabalhar.[...]

[Meu marido] só ajudava um pouco com as crianças, mas a comida, janta, tudo era eu. Eu achei que eu me saí muito bem [...] com trabalho, criança e casa. (Nazaré).

Para além das complicações associadas à gravidez na adolescência, as evidências extraídas das narrativas revelam "o caráter indissociável entre classe social e gênero na compreensão [desse] fenômeno" (Heilborn et al., 2002, p. 13). Muitas são as consequências negativas frequentemente associadas a uma gravidez não planejada, entre as quais os prejuízos decorrentes da eventual descontinuidade do progresso acadêmico e até mesmo a evasão escolar definitiva, com potencial repercussão no desenvolvimento profissional futuro (Bynner \& Parsons, 2002). Dentre as entrevistadas, verificou-se a menção ao abandono dos estudos em decorrência das demandas geradas pela maternidade, ainda que em alguns casos, como o de Monique, a evasão escolar já tivesse ocorrido anteriormente, em virtude do ingresso precoce no mercado de trabalho informal:

Eu estudei, eu fiz até a oitava série, né? [...] e quando eu engravidei com 16 eu parei. [...] alguns anos atrás eu voltei a estudar, eu fiz o... eu fiz até... eu terminei o primeiro grau todinho, mas eu não pensei, pensei que eu não tinha mais idade, parei, não fui concluir o segundo grau porque na verdade o professor de história, ele perguntou "dona Georgette o que que a senhora pensa... a senhora tá estudando pra que, tá pensando em quê?", mas eu não fui, eu queria estudar, então eu num... falei "não vou estudar mais" (Georgette).

Ele [marido] não deixava [trabalhar], pra poder ficar em casa cuidando dela [filha]. [...] [Após o seu nascimento] eu não trabalhava, porque eu fiquei esse tempo todo tomando conta dela, cuidando dela. $\mathrm{E}$ aquilo ali eu ficava igual uma Amélia, como dizem hoje em dia, né? Só lavava, passava, cuidava dentro de casa, não conhecia a vida, não conhecia nada, então eu acho que eu joguei muito a minha juventude fora. Me arrependo da minha filha até hoje, aí me dando trabalho, entendeu? (Monique). 
O abandono dos estudos foi apontado, por algumas entrevistadas, como a causa da falta de opções profissionais qualificadas que se fizeram presentes, em suas trajetórias. Destaca-se, ademais, a assunção de responsabilidade individual por não terem prosseguido com os estudos:

Minha mãe nunca quis que eu trabalhasse nessa área [serviços gerais]. Ela queria que eu fizesse alguma coisa, estudasse, fosse pra qualquer emprego, mas auxiliar de serviços é bom como qualquer outro. [...] Aconteceu porque eu não terminei meus estudos. Se tivesse terminado, talvez eu não teria essa profissão. (Alessandra).

Agora eu quero terminar de estudar pra mim arrumar um trabalho bom. [...] Eu quero fazer qualquer coisa, menos trabalho de limpeza, entendeu? [...] Eu quero fazer uma casa pra mim. (Bruna).

Em linhas gerais, julga-se, à luz do quadro teórico proposto, que a maior probabilidade de ocorrência tanto de casos de gravidez precoce quanto de sua reincidência no curto prazo em jovens das classes trabalhadoras associa-se, potencialmente, a um quadro mais amplo de falta de planejamento das atividades, cotidianas ou não (MacDonald \& Marsh, 2005). Essa ausência de planejamento, no caso das entrevistadas, impactou nas trajetórias profissionais das entrevistadas, marcadas pela descontinuidade e pela incerteza. A passagem por diferentes e igualmente precárias ocupações sinaliza um percurso feito ao sabor das oportunidades que se apresentavam vis-à-vis à urgência das privações materiais vivenciadas pelas entrevistadas. A carreira de Bruna, narrada em primeira pessoa, é um exemplo paradigmático de tal fenômeno.

Eu comecei a trabalhar bem nova, que eu tive filho nova, com 13 anos. Aí com 14 eu comecei a trabalhar, mas era segurando uma faixa lá na fila da Barra da Tijuca. Aí eu fiquei uns 3 meses [...]. Aí depois fui trabalhar numa fábrica de doces, aqui na Major Fonseca. Ali eu fiquei bastante tempo, eu entrei e sai umas três vezes, que ele [filho] era bem pequeno. [...] Aí depois eu fui e voltei de novo, fiquei mais não sei quantos anos, aí saí. Aí depois eu arrumei um trabalho de carteira assinada, que foi aqui na cancela, na Jepa. Ali eu fiquei 10 meses. [...] Aí depois eu fui trabalhar em Botafogo, na Inspetran, de limpeza. Aí fiquei lá uns 3 meses, aí a empresa fechou. [...] Voltei pra casa de doces de novo, fiquei lá um bom tempo. [...] Aí saí de lá, fiquei em casa uns cinco meses, aí eu voltei e fui trabalhar lá na Impacto [firma de limpeza]. [...] Aí eu fique dois anos e cinco meses, e aí eu tive minha filha. [...] Então, eu achei que ia ser muito contramão com criança pequena, aí pedi pra sair da empresa. Aí eu fiquei quase dois anos e comecei a trabalhar agora [na Limpo, firma de limpeza]. (Bruna).

As narrativas das entrevistadas revelam uma configuração existencial específica, na qual a relação com a dimensão temporal assenta-se na valorização do momento presente, reflexo de um contexto familiar caracterizado por uma necessidade material acentuada e premente, traços característicos da noção de habitus precário, nos termos descritos por Souza (2012a). Consequentemente, suas formas de agir, pensar e sentir pouco se assemelham às disposições socioeconômicas usualmente vinculadas à noção abstrata de "ator racional", provido de senso de agência e orientado por objetivos (Souza, 2012b; Barret, 2015), disposições essas que poderiam conduzi-las a percursos que as afastassem, minimamente, de suas precárias condições de origem. Em contraposição, os relatos das entrevistadas correspondem à constituição de um habitus precário que combina baixos níveis de capital com uma estrutura familiar desorganizada. Argumenta-se que é impossível dissociar tais condicionantes das trajetórias ocupacionais trilhadas pelas entrevistadas, marcadas por ocupações precárias e escassas possibilidades de ascensão. Tais condicionantes contribuem para o questionamento das abordagens voluntaristas de carreiras que, ao enfatizarem a agência individual, desconsideram o peso do contexto na escolha e no transcurso das carreiras.

\section{Considerações finais}


As histórias de vida das interlocutoras desta pesquisa - trabalhadoras que atuam como faxineiras terceirizadas - contrapõem-se aos argumentos que julgam plausível a possibilidade de se traduzir toda e qualquer trajetória pessoal como do tipo "faça você mesmo" (Beck, 1997). Em contrapartida, essas trajetórias emergem como representações de um mundo do trabalho fragmentado, constituído não somente por carreiras trilhadas por "produtores informacionais", mas também por aquelas percorridas por um significativo contingente de trabalhadores agrupados sob a rubrica "mão de obra genérica substituível" (Castells, 1999, p. 423).

Em oposição às modalidades de carreira como as "sem fronteiras" (Arthur \& Rousseau, 1996) e a "proteana" (Hall \& Moss, 1998), que privilegiam, sobremaneira, a agência, as histórias das entrevistadas iluminam a existência de múltiplas fronteiras que restringem o conjunto de escolhas e de estilos de vida à sua disposição. Tomadas em conjunto, a sociologia disposicional bourdieusiana e a sua apropriação crítica por Souza (2012a) permitiram articular a reprodução social com o desenvolvimento de um habitus precário, caracterizado pela conjugação de baixos níveis de capitais econômico, cultural e familiar. Esta última modalidade de capital caracteriza-se especialmente por uma relação muito particular com a dimensão temporal, avessa ao desenvolvimento de disposições associadas ao cálculo, à previsão e ao pensamento prospectivo (Souza, 2009). Entre os temas que emergiram nas narrativas destacam-se a reprodução sócio-ocupacional familiar como regra, a normalização da precariedade e a relação com o tempo, a gravidez precoce e um habitus precário.

No que diz respeito às contribuições do artigo, a análise empreendida permitiu que se desnudasse o contexto de precariedade a partir do qual as trajetórias profissionais das entrevistadas foram sendo construídas. Foi difícil dissociar a origem social desfavorecida das trabalhadoras, condicionante do habitus precário, da atuação profissional em uma carreira situada no extremo inferior da hierarquia ocupacional, reforçando-se, assim, a pertinência de tal construto. Defende-se, ainda, que os resultados deste artigo emergem como um contraponto ao pressuposto dominante no campo de estudos de carreiras sob a perspectiva organizacional, que prega a homogeneização de modalidades de carreira caracterizadas pela ênfase na agência. A aproximação de casos concretos, a exemplo das histórias de vida das interlocutoras desta pesquisa, ilustra a importância de se relativizar esse pressuposto, subjacente à tendência dominante no referido campo. Finalmente, a opção pelo estudo das trajetórias de faxineiras contribuiu para agregar aos estudos de carreiras um contingente significativo de indivíduos desconectados das redes de poder, cujas carreiras se tornam, em última instância, invisíveis. Nesse sentido, a contribuição social do presente trabalho residiu em dar visibilidade a um contingente expressivo de trabalhadores cujas trajetórias e vicissitudes são pouco conhecidas.

Entre as limitações do artigo, destaca-se o fato de a análise empreendida focar, primordialmente, o marcador classe social e, em menor grau, as questões de gênero e raça. Futuras pesquisas podem deterse sobre a dimensão da interseccionalidade (Colling, Oltramari, \& Rodrigues, 2018), avaliando potenciais impactos da "tríade minoritária" (mulheres, negras e pobres) sobre o desenvolvimento profissional. Reconhece-se, assim, a impossibilidade de se fugir à intrínseca associação entre raça e desigualdade no cenário nacional, sobretudo em virtude da base escravocrata sobre a qual foi erigida a sociedade brasileira, relacionada por sua vez à divisão sexual do trabalho (Rosa, 2016). Contudo, o recorte proposto neste artigo fundamentou-se no diagnóstico de Souza (2012a), para quem o processo de (re)produção histórica do habitus precário não alcança tão somente os contingentes de negros e pardos, mas também outros grupos raciais lançados à própria sorte com o advento da abolição da escravatura, sem o devido processo de inserção social e cultural. Em linha com a tese de Souza (2012a), as histórias de vida narradas pelas interlocutoras desta pesquisa, majoritariamente negras, evidenciam um pano de fundo assentado sobre um processo de violência sociossimbólico, em que se conjugam forças ambientais e circunstâncias pessoais adversas, com destaque para o processo de desorganização familiar e para os altos níveis de precariedade material e existencial. 
Em termos de pesquisas futuras, sugere-se a ampliação do foco de análise dos estudos de carreira para abarcar distintas carreiras e não apenas as gerenciais, profissionais e hierárquicas. Acredita-se que tal mudança tem grande potencial de contribuir não só do ponto de vista científico, mas também do prático, uma vez que tem o poder de municiar as organizações com informações que representem múltiplas dimensões das carreiras dos diferentes grupos de profissionais em seu interior.

\section{Referências}

Antunes, R. \& Druck, G. (2014). A epidemia da terceirização. In R. Antunes (Org.). Riqueza e miséria do trabalho no Brasil. v.3. (pp. 13-24). São Paulo: Boitempo.

Arthur, M.B. \& Rousseau, D. (1996). The boundaryless career as a new employment principle. In M.B.

Arthur, \& D. Rousseau (Eds.). The boundaryless career: a new employment principle for a new organizational era (pp.3-20). Oxford: Oxford University Press.

Atkinson, W. (2012). Reproduction revisited: comprehending complex educational trajectories. The Sociological Review, 60, 735-53.

Barrett, T. (2015). Storying Bourdieu: Fragments Toward a Bourdieusian Approach to "Life Histories". International Journal of Qualitative Methods, 14(5), 1-10.

Barros, V.A. \& Lopes, F.T. (2014). Considerações sobre a pesquisa em história de vida. In E. M. Souza (Org.). Metodologias e analíticas quantitativas em pesquisa organizacional: uma abordagem teóricoconceitual (pp. 41-63). Espírito Santo: Edufes.

Baruch, Y. \& Vardi, Y. (2016). A fresh look at the dark side of contemporary careers: Toward a realistic discourse. British Journal of Management, 27(2), 355-72.

Beck, U. (1997). A reinvenção da política: rumo a uma teoria da modernidade reflexiva. In U. Beck, A. Giddens, \& S. Lash. Modernização reflexiva: política, tradição e estética na ordem social moderna (pp.1171). São Paulo: Editora Unesp.

Bezuidenhout, A. \& Fakier, K. (2006). Maria's burden: Contract cleaning and the crisis of social reproduction in post-apartheid South Africa. In L. Aguiar \& A. Herod (Eds.). The dirty work of neoliberalism (pp. 37-59). Malden: Blackwell Publishing.

Bertaux, D. (1999). El enfoque biográfico: su validez metodológica, sus potencialidades. Proposiciones, 29, 1-23.

Blustein, D. et al. (2002). Voices of the forgotten half: the role of social class in the school-to-work transition. Journal of Counselling Psychology, 48(3), 311-323.

Bourdieu, P. (1979). O desencantamento do mundo: estruturas econômicas e estruturas mentais. São Paulo: Perspectiva.

Bourdieu, P. (1990). The logic of practice. California: Stanford University Press, 1990.

Bourdieu, P. (1995). A dominação masculina. Educação \& Realidade, 20(2), 133-184.

Bourdieu, P. (1999). The weight of the world. California: Stanford University Press.

Bourdieu, P. (2004). A formação do habitus econômico. Sociologia, 14, 9-34.

Bourdieu, P. (2005). A ilusão biográfica. In J. Amado \& M. M. Ferreira. Usos \& abusos da história oral (pp. 183-191). Rio de Janeiro: Editora da FGV.

Bourdieu, P. (2010). O poder simbólico. Rio de Janeiro: Bertrand Brasil.

Bourdieu, P. (2013). A distinção: crítica social do julgamento. Porto Alegre: Editora Zouk.

Bourdieu, P. (2015). Os três estados do capital cultural. In M. A. Nogueira \& A. Catani (Orgs.). Escritos de educação (pp.79-88). Petrópolis: Vozes.

Bourdieu, P., Chamboredon, J.C., \& Passeron, J.C. (2005). Ofício de sociólogo: metodologia da pesquisa na sociologia. Petrópolis: Editora Vozes. 
Bourdieu, P. \& Wacquant, L.J.D. (1992). An invitation to reflexive sociology. London: The University of Chicago Press.

Bynner, J. \& Parsons, S. (2002). Social exclusion and the transition from school to work: the case of young people not in education, employment, or training (NEET). Journal of Vocational Behavior, 60, 289-309.

Castells, M. (1999). A era da informação: economia, sociedade e cultura (v. 3). São Paulo: Paz e Terra.

Colling, T., Oltramari, A.P., \& Rodrigues, M.B. (2018). Enegrecendo a carreira. Congreso Internacional de la Red Pilares, Santiago, Chile, 5.

Costa, F. B. (2004). Homens invisíveis: relatos de uma humilhação social. São Paulo: Globo.

Costa, F. B. (2008). Moisés e Nilce: retratos biográficos de dois garis. Tese (Doutorado em Psicologia) Universidade de São Paulo, São Paulo.

Costa, S. G. (2007). O pai que não é o patrão: vivências de sujeitos terceirizados no Ministério Público do Estado do Rio Grande do Sul. Organização \& Sociedade, 14(42), 97-113.

Côté, S. (2011). How social class shapes thoughts and actions in organizations. Research in organizational behavior, 31, 43-71.

Denzin, N.; Lincoln, Y. (2010). A disciplina e a prática da pesquisa qualitativa. In N. Denzin \& Y. Lincoln (Orgs.). O planejamento da pesquisa qualitativa: teorias e abordagens. São Paulo: Artmed.

Diogo, M. F. \& Maheirie, K. (2007). De balde e vassoura na mão: os sentidos que mulheres serventes de limpeza atribuem aos seus trabalhos. Revista Mal-Estar e Subjetividade, 7(2), 557-579.

DIEESE. (2011). Perfil dos trabalhadores em asseio e conservação e limpeza urbana de São Paulo. São Paulo: SIEMACO.

Eggenhofer-Rehart, P.M. et al. (2018). Refugees' career capital welcome? Afghan and Syrian refugee job seekers in Austria. Journal of Vocational Behavior, 105, 31-45.

Emirbayer, M. \& Johnson, V. (2008). Bourdieu and organizational analysis. Theory and Society, 37,1-44. Eshelman, A.J. \& Rottinghaus, P.J. (2015). Viewing adolescents' career futures through the lenses of socioeconomic status and social class. Career Development Quarterly, 63, 320-332.

Fernandes, F. (1978). A integração do negro na sociedade de classes: ensaio de interpretação sociológica. São Paulo: Globo.

Fernando, W.D.A., Cohen, L., \& Duberley, J. (2018). What helps? Women engineers' accounts of staying on. Human Resource Management Journal, 28(3),479-495.

Foster, W.M., Hassard, J.S., Morris, J., \& Wolfram, C.J. (2019). The changing nature of managerial work: The effects of corporate restructuring on management jobs and careers. Human Relations, 72(3),473504.

Guest, D.E. \& Sturges, J. (2007). Living to work: working to live: conceptualizations of careers among contemporary workers. In H. Gunz \& M. Peiperl (Eds.). Handbook of career studies (pp. 13-38). California: Sage Publications.

Gunz, H. \& Mayrhofer, W. (2015). The social chronology framework: A multiperspective approach to career studies. SSRN. Recuperado em 08 de março, 2018, de https://ssrn.com/abstract=2595568.

Hall, D.T. \& Moss, J.E. (1998). The new protean career contract: helping organizations and employees adapt. Organizational Dynamics, 26(3),22-37.

Hardie, J.H. (2016). Daughters of the great recession: young women's school, work, and Family pathways in the transition to adulthood. Work and Family Researchers Network Meeting, Washington, United States, 3.

Heilborn, M.L et al. (2002). Aproximações socioantropológicas sobre a gravidez na adolescência. Horizontes Antropológicos, 8(17),13-45. 
Herod, A. \& Aguiar, L. L. M. Introduction: cleaners and the dirty work of neoliberalism. In. L. Aguiar \& L. L. M. Herod (Eds). The dirty work of neoliberalism. (pp. 1-10). Malden: Blackwell Publishing, 2006. Iellatchitch, A., Mayrhofer, W., \& Meyer, M. (2005). Career habitus revisited: Complicated and incomprehensible answers to questions nobody asked? Vienna: Wirtschaftsuniversität Wien. Recuperado em 10 março, 2020 de https://www.wu.ac.at/fileadmin/wu/o/vicapp/ egos_2005_habitus_revisited.pdf.

Inkson, K., Gunz, H., Ganesh, S., \& Roper, J. (2012). Boundaryless careers: bringing back boundaries. Organization Studies, 33(3),323-40.

Kendig, S.M., Mattingly, M.J., \& Bianchi, S.M. (2014). Childhood poverty and the transition to adulthood. Family Relations, 63, 271-286.

King, N. (2004). Using templates in the thematic analysis of text. In C. Cassell \& G. Symon. Essential guide to qualitative methods in organizational research. (pp. 256-278). London: Sage.

Kost, D., Fieseler, C., \& Wong, S. I. (2020). Boundaryless careers in the gig economy: An oxymoron? Human Resource Management Journal, 30(1),100-113.

Lara, S. M., Marra, A.V., \& Fernandes, P.C.M. (2020). Building the professional identity in an outsourcing environment. Gestão \& Regionalidade, 36(109), 182-197.

MacDonald, R. \& Marsh, J. (2005). Disconnected youth? Growing up in Britain's poor neighbourhoods. New York: Palgrave Macmillan.

Mattos, P. (2006). A mulher moderna numa sociedade desigual. In: Souza, J. (Org.). A invisibilidade da desigualdade brasileira (pp. 153-196). Belo Horizonte: Editora UFMG.

Mayrhofer, W., Meyer, M., \& Steyrer, J. (2007). Contextual issues in the study of careers. In H. Gunz \& M. Peiperl (Eds.). Handbook of career studies (pp.215-240). California: Sage Publications.

McDonald, P., Pini, B., Bailey, J., \& Price, R. (2011). Young people's aspirations for education, work, family and leisure. Work, employment and society, 25(1), 68-84.

Meira, F.G.G., Gomes, A.F., \& Amaral, M.S. (2019). O Trabalho de Gari: Das motivações às expectativas profissionais. Gestão \& Conexões, 8(3),52-71.

Moore, C., Gunz, H., \& Hall, D.T. (2007). Tracing the historical roots of career theory in management and organization studies. In H. Gunz \& M. Peiperl (Eds.). Handbook of career studies (pp.13-38). California: Sage Publications.

Plomp, J. et al. (2016). Career competencies and job crafting: How proactive employees influence their well-being. Career Development International, 21(6),587-602.

Pochmann, M. (2014). O mito da grande classe média: capitalismo e estrutura social. São Paulo: Boitempo.

Roper, J., Ganesh, S., \& Inkson, K. (2010). Neoliberalism and knowledge interests in boundaryless careers discourse. Work, employment and society, 24(4),661-679.

Rosa, A. R. (2016). Gênero e pós-colonialismo. In A. P. Carrieri, J. C. Teixeira, \& M. C. R. Nascimento (Orgs.). Gênero e trabalho: perspectivas, possibilidades e desafios no campo dos estudos organizacionais (pp. 57-94). Salvador: Edufba.

Schoon, I., Peter, M., \& Ross, A. (2007). Career transitions in times of social change: his and her story. Journal of Vocational Behavior, 70, 78-96.

Silva, C. S., Bortolini, A. C. S., \& Oltramari, A. P. (2018). Relações de trabalho e cinema: uma análise do filme "Que horas ela volta?". Farol: Revista de Estudos Organizacionais e Sociedade [recurso eletrônico], 5(12),130-197.

Souza, J. (2006). A gramática social da desigualdade brasileira. In J. Souza (Org.). A invisibilidade da desigualdade brasileira (pp. 23-53). Belo Horizonte: Editora UFMG.

Souza, J. (2009). A ralé brasileira: quem é e como vive? Belo Horizonte: Editora UFMG. 
Souza, J. (2012a). A construção social da subcidadania: para uma sociologia política da modernidade periférica. Belo Horizonte: Editora UFMG.

Souza, J. (2012b). Os batalhadores brasileiros: nova classe média ou nova classe trabalhadora? Belo Horizonte: Editora UFMG.

Sullivan, s. E.; Baruch, Y. (2009). Advances in career theory and research: a critical review and agenda for future exploration. Journal of Management, v. 35, n. 6, p. 1542-1571.

Taber, B. J. \& Blankemeyer, M. (2015). Future work self and career adaptability in the prediction of proactive career behaviors. Journal of Vocational Behavior, 86, 20-7.

Taylor, C. (2013). As fontes do self: a construção da identidade moderna. $4^{a}$ edição. São Paulo: Edições Loyola.

Tempest, S. \& Coupland, C. (2017). Lost in time and space: temporal and spatial challenges facing older workers in a global economy from a career capital perspective. The International Journal of Human Resource Management, 28(15), 2159-2183.

Tomlinson, J., Baird, M., Berg, P., \& Cooper, R. (2018). Flexible careers across the life course: Advancing theory, research and practice. Human Relations, 7(1), 4-22.

Van der Heijden, B.I.J.M. \& De Vos, A. (2015). Sustainable careers: introductory chapter. In A. de Vos \& B, I.J.M. Van der Heijden. Handbook of research on sustainable careers (pp. 1-19). Cheltenham: Edward Elgar Publishing. 